\title{
Challenges and Coping Strategies for Parents with Autistic Children
}

\section{Agyekum HA*}

Department Geography and Resource Development Psychology, University of Ghana, Ghana

\begin{abstract}
Studies so far look at the causes and cure for autism, however, little work has been done on the challenges parents of these children face in their upbringing. This study brought out the challenges that parents with autistic children face as well as the coping mechanisms these parents adopt in their quest to cater for their children. Semi structured interviews were used as a form of data collection. Prominent themes the study highlights is the challenges of parents, which was associated with the inability of the parents to have meaningful conversations with their children, the financial burden of taking care of them, stigmatization of their autistic children as well as themselves, and the demandingness of the autistic children. With these problems, parents in the study adapted to their situation by accepting the situation of their wards, depending on God for strength, receiving support and encouragement from some family members and friends, joining support groups, as well as taking leave from work to help their children seek proper medical care.
\end{abstract}

Keywords: Autistic children; Coping strategies

\section{Introduction}

Autism Spectrum Disorder is a very common developmental disability which occurs in 1 out of 110 children over the world [1]. The term has been defined by Bolte [2] as "a neurodevelopmental disorder persisting deficits in social interaction across multiple contexts, alongside restricted, repetitive patterns, interests, or activities as manifested by at least two prototypically inflexible behaviors." Due to its similarity with other disorders like Asperger Syndrome, Atypical Autism and Disintegrative Disorder, the term was changed from Autism to Autism Spectrum Disorder [3]. There is no exact cause for autism $[1,3]$ however, there are speculations of it being caused either genetically or by environmental factors [3]. In a similar vein, there is no known cure for the disability $[1,4]$, there is therefore the need for early therapeutic treatment [1].

Parents with autistic children daily go through challenges. These challenges may be the inability of the children to fend for themselves, the child's educational challenges and the stigma and stereotypes that comes with having a child with Autism Spectrum Disorder. At the age of two, most children should be toilet trained; however, this is not the case with children living with autism. At that age they would still have to be assisted in almost every facet of their lives. It makes it very stressful for their caretakers especially their mothers [5]. Although the symptoms of autism tend to last for a long period of time, it is stated that, it is more difficult for the parents to take care of the child when he is younger [6] or when the child is a toddler [7].

Stigma and stereotyping is a very common issue for parents with children with autism. The mere fact that parents have a child with that condition is a very hard thing to accept and the situation is made worse when the society instead of giving a helping hand stigmatize you. McCabe [8] is of the view that stigma is a major challenge of parents with children with autism. This stigma is heightened by the embarrassing comments that people make when they first realize a parent has a child with that condition [9].

Even though, all these challenges are faced by parents with autistic children, much work has not been done in Ghana to ascertain the particular problems that these parents are facing. With this, there is the need for a research work that will look at the challenges that parents with autistic children in Greater Accra, the capital city of Ghana go through in their daily lives.
Knowing the challenges parents with children with autism face would constitute grounds for support to be given to them by professionals. If the challenges the parents are going through are clearly spelt out, therapists who deal with the families of children with this disorder will know the type of treatments to provide, even if it has not been asked for. Aside helping therapeutic professionals, the findings will also inform the teachers at special schools as to how to draw their curriculum to meet the needs of the autistic children. This goes to show that the findings of this work will make meaningful contributions to policy making, research and practice. The aim of this study is therefore to find out the challenges and coping strategies adopted by parents with autistic children.

\section{Methods}

The current study is designed to have a qualitative background, using the phenomenological approach. This research design was selected to assist the researcher get a better understanding of the experiences faced by parents of children with ASD and also help in gaining the opportunity to observe the nonverbal cues, aside the spoken word from the interviews that were conducted.

The study was conducted in the Greater Accra region of Ghana. Majority of the research work was done at PACID, an institution for parents who have children with disabilities and certain parts of Accra.

A total number of ten parents were interviewed for the purpose of this research. To ensure gender representation, the researcher interviewed two male parents and seven female parents. One of the participants was a sister who was taking care of her brother who had autism. There were variations in occupation, which included both the formal and informal sectors of the Ghanaian economy. Most of the

*Corresponding author: Agyekum HA, Department Geography and Resource Development Psychology, University of Ghana, Ghana, Tel: 233505517635; E-mail: haagyekum1@gmail.com

Received August 02, 2018; Accepted August 08, 2018; Published August 16 2018

Citation: Agyekum HA (2018) Challenges and Coping Strategies for Parents with Autistic Children. J Ment Disord Treat 4: 166. doi:10.4172/2471-271X.1000166

Copyright: (๑) 2018 Agyekum HA. This is an open-access article distributed under the terms of the Creative Commons Attribution License, which permits unrestricted use, distribution, and reproduction in any medium, provided the original author and source are credited. 
participants had one out of their children being autistic, there was however a parent that had male twins being children with autism. Five of the parents in this study constitute older parents while the other five were categorized as younger parents.

The study developed a semi-structured instrument as a guide in the data collection process. It used semi-structured instrument to allow flexibility in a manner that helped questions to flow. Each interview spanned between fifteen to forty minutes.

\section{Results}

Theme 1: Challenges faced by parents with children with autism spectrum disorder

Financial burden: All parents spoke about financial burden. They complained that, taking care of children with autism in Ghana was expensive. They attributed their financial difficulties to the expensive treatments that the children required periodically. A mother expressed how she spends a lot when it comes to the treatment of her child:

Taking care of my son is very expensive since I am a single mother. It is sometimes overwhelming, the routine scans to check on the improvements that the child is making and what medicines will be appropriate at a particular time is very expensive (Participant 2).

Another item that expanded the financial burden of the parents was transportation of the autistic child. Parents shared that they have to always take "dropping" to prevent them from having to face people who were not ready to accept their children or make any contacts with them. For example, a father described his experience:

When going somewhere with him, you always have to take dropping to avoid avid statements made by others when you pick public transport (Participant 4).

It was realized that although the parents at the school were complaining about finances, they did not cite it as though it was weighing them much, but the participant from outside PACID showed much challenges financially. Being an unemployed mother, whose husband has stopped taking care of their autistic twin children she had this to say:

I had to stop sending them for treatment because of the cost; I am actually looking for a school that offers free education to autistic children because I cannot afford the fees at the private schools (Participant 10).

The accounts of the parents revealed that, there are parents who have enough resources to cater for the treatment of their children though they find it expensive, but there are others who struggle to cater for their children and also in obtaining services for them.

Stress from childcare duties: Caregiving to autistic children is not an easy task. Parents in this study expressed how difficult it was to take care of their children. Most of them, especially the younger parents complained that their autistic children could not do anything for themselves. For example, a mother said she had to do everything for her son right from when he wakes up till he goes back to bed (Participant 5). Autistic children tend to make a fuss about a change in their regular routine.

Parents also complained of having to take care of them after school without much assistance from nannies and other family members. Since they need help with everything, there should be someone who is always taking care of them and this is quite difficult to find, even if the parents are willing to pay them. A mother shared in this sentiment as she complained about the number of times she had to change nannies (Participant 9). There were some parents who were privileged to have some family members helping them out. For example, a mother shared that, she had a sister who helped her in taking care of her child after school (Participant 5). One parent had a nanny who was helping with the childcare responsibilities, but majority of the parents complained of being unable to find someone to cater for their children when they were busy.

Communication barriers: Not being able to communicate is one of the major characteristics of autism. Parents found it very stressful that their children could not hold conversations with them. Their challenge lied in the fact that the children could not say what was wrong with them. The parents, especially the older ones were of the view that with time the child's communication pattern improved. Though they could not make full sentences, they could make out some words. For example, a mother shared her experience on communication with her child as:

Once a while when she wants to converse we do, there are some of the things I can't understand and I feel bad about it because I wish I understood her and could respond positively but I can't. But generally we are getting along well (Participant 3).

Stigma: Stigma was seen to be handled well in older parents than among younger parents. Older parents shared that, when you outwardly express, your love for your autistic child it not only makes them feel comfortable but also helps others accept them. As such, when people try to stigmatize the child, the parent should show the child a stronger love in the presence of those who stigmatizes them. A young mother however spoke emotionally about how her child who is in a mainstream school was being treated:

The parents there practically tell their children not to talk to him [child] and the teacher leaves him unattended to (Participant 9).

However, there are parents who do not think their children are being stigmatized in any way. For example, a mother shared her experience with her daughter at church as:

"People in our church find her to be very lively so they do not treat her differently, but I always sit together with her to monitor her." (Participant 3).

Parents in this study always have to deal with people who do not want to come into contact with their children because of their disability. For example, a father mentioned that people usually do not want to sit by him in a car (Participant 4).

Society's reaction to the autistic child: Parents in one way or the other have to contend with their autistic children interacting with the world. The parents were of the view that when they take the children out, they usually comport themselves, especially when you explain to them and ask them to corporate. However, when they are hyper, they will throw tantrums here and there. A father for instance shared how he attends to his autistic child in public by saying:

I always have to sit by him [child]. I first explain to the person sitting by me as to how my child might behave, and I tell him [child] to comport himself and he might listen when he wants to, but if he does not I have to leave as soon as I can (Participant 4).

More often than not, parents are met with a stigmatizing attitude from the people who come in contact with their children. From the interviews, it was realized that the older parents dealt well with these reaction as compared with the younger parent. Younger parents always 
felt discouraged and usually stayed away from public view while the older adults proudly went out with their child and stood up for them when the need arose. A younger parent had this to say on how society reacts to her child:

People are always asking me what is wrong with my child, I feel bad so I just don't go out with her (Participant 6).

An employed mother who lived in a compound house had this to share on how the society reacted towards her children. She bitterly spelt out how her house mates treated her children,:

I get no help with my kids and the tenant beat them when I am not around, so I have to lock them up when am going to sell (Participant 10).

Theme 2: Coping strategies adopted by parents with autistic children.

Relying on spirituality: From the interviews, to be able to cope with all this, parents usually relied on God. Though majority believed the cause of the disorder was medical, they found solace in the spiritual. They relied on the Supreme Being to give them strength to deal with their situation and cater for their children. Parents encouraged themselves that it was a test from God and he will see them through (Participant 8). Some parents believed that as a parent with an autistic child, you do not have to complain but just pray to God for strength (Participant 4). Some parents even believed that what their children will become in some years to come was dependent on God (Participant 4).

There were parents who believed that the cause of the disorder was spiritual as such, spiritual solutions should be given to the child. A participant shared this on the treatment her children received:

My mother and I have being taking them to herbalists to try and cure them (Participant 10).

Acceptance: Some parents especially the older ones had accepted their situation and moved on. These parents started that, the only way you can cope is when you accept the situation and find ways to deal with it. A parent described how she copes with her child every day. She sounded very proud of herself as she said:

You have to forget about the challenges and focus on moving on. I take care of him so well that when you see him you will not even know he is sick until I tell you (Participant 5).

Encouragement from family and friends: Parents in this study received encouragement from family and friends when they were in hard times. For example, one mother explained that she is always encouraged by the words her mother spoke to her. She described the first incident when she first heard of the situation:

My mother just tapped my shoulder, smiled and said, my daughter, you would still have become the great person you are if you had autism. The mother determines what her child will become, I believe in you so you have to believe in yourself. From that time onwards I focused on making my daughter a better person (Participant 6).

Theme 3: Support systems available for parents with autistic children.

Support groups: Parents were all part of PACID which served as a support group that educated them on how to take care of their children. For instance, a mother in the study answered to if she was in any support group by saying:

Well I am a part of PACID. It is actually the only place I can freely express myself on what I am going through with my child (Participant 9).
Parents in this study shared during the interview how PACID has been of immerse help to them throughout they joining the group.

Support from family: In this study, support parents received was from their families, usually the maternal grandmothers of the children with autism. All of the female parents said they received help from their mothers, with the exception of an older mother and a lady who was taking care of her brother. One young mother said she mostly takes care of her baby but her mother supports her in every way possible (Participant 6). Some parents in this study also get support from other family members as well as their family as a whole. Most of them said help did not come in frequently but they do come. A parent who had her whole family giving her emotional support had this to say when questioned:

The whole family supports me since I am the first to have an autistic child (Participant 5).

In as much as the female parents shared the support they received from their family, it was however realized that no father shared that they received help from any family member. For instance, a father said that, Ghana now practices a nuclear family system so no one has to help you take care of your child (Participant 8).

Support from work place: Aside the family system, parents in the formal sector also had their immediate supervisors giving them some privileges such as reporting at a later time or giving the parent some time off work to cater for the child whenever the need arose. A parent gratefully said this when interviewed:

My boss has been so flexible to allow me to bring her to school (Participant 8).

\section{Discussions and Conclusion}

The number of parents bringing forth children with Autism Spectrum Disorder is on an increase worldwide, to which Ghana is not an exception [3]. Taking care of children with autism comes with a lot of challenges, it is against this that this study seeks to explore the challenges parents with autistic children in Greater Accra face and the coping strategies they adopt. The study delved into the challenges and the coping mechanisms that parents with autistic children had adopted.

The challenges that parents with autistic parent face are financial burden, stigma, challenges in performing childcare duties, and inability to communicate with children. The study realised that the parents bear escalating financial burden because of the expensive cost associated with the routine medical scans and check-ups that children had to get in relation to their intervention and the cost of transporting children with autism in Ghana. Another cost that parents complained about was the amount that they had to pay as school fees for their autistic children in school. These pose financial burden on parents as they complained that they would not have to bear this cost had they had children without autism. In a similar fashion, parents faced stigma whenever they went to public gatherings with their autistic children. Ghanaians perception of persons with autism made it such that whenever parents with autistic children sent their children out they had to go through the judgemental stares and avid statements that people passed. Parents having their autistic children in mainstream schools complained of isolation and discrimination against their children. This caused the parents emotional stress as they were offended their children were being discriminated upon. Adding on to the challenges, the demandingness of autistic children where parents had to help them in doing every activity caused parents higher levels of stress. Since the 
Citation: Agyekum HA (2018) Challenges and Coping Strategies for Parents with Autistic Children. J Ment Disord Treat 4: 166. doi:10.4172/2471271X.1000166

Page 4 of 4

parents had to be with them throughout every activity they performed. Parents in the study also shared that the inability of their children to communicate with them frustrated them. Due to this, the parents did not know what exactly their children wanted at a particular time.

In dealing with these challenges they show resilience and ask for grace from God to help them with the challenges. Ghanaians have a spiritual worldview; as such these parents are of the opinion that they can leave everything in the care of God. Parents also received encouragement from family and friends which helped them to cope with their situations. Parents in this study also joined support groups where they learn about the disorder as well as seek encouragement from one another. Superiors also gave parents in this study some hours off work to attend to their children.

Social workers have to stand up for parents with autistic children. They can do this by advocating for higher fringe benefits for workers, engaging in public education to help parents know about the disorder and also making information available to the public in order to reduce the stigma attached to having a child with autism.

\section{Acknowledgement}

I am grateful to God for making this study a success. I am immensely grateful to my supervisor Dr. Kingsley Saa-Touh Mort for his guidance and suggestions throughout this work. I also appreciate the efforts of my parents who supported and provided me with all my needs throughout my stay in the university. I also wish to thank everyone in my family for their enormous support during the course of my study. This appreciation will not be complete without mentioning Dr. Akosua Darkwah of University of Ghana, Sociology Department. My appreciation also goes to New Horizon Special School Staff for their mammoth contribution. I thank them for their support and time throughout the period of my research work.

Finally, my gratitude goes to all others who helped in any way but could not be mentioned. To all I say thank you, I appreciate your efforts.

\section{References}

1. Speaks $A$ (2011) What is autism?

2. Sven B (2014) The power of words: Is qualitative research as important as quantitative research in the study of autism 18: 67-68.

3. Baker C, Wuest J, Stern PN (1992) Method slurring: the grounded theory/ phenomenology example. J Adv Nurs 17: 1355-1360.

4. Siegel B (2003) Helping children with autism learn: Treatment approaches for parents and professionals. Oxford university press.

5. Boyd BA (2002) Examining the relationship between stress and lack of social support in mothers of children with autism. Focus on Autism and Other Dev Disabilities 17: 208-215.

6. Bristol MM, Schopler E (1983) Stress and coping in families of autistic adolescents and Springer US.

7. Schertz HH, Odum SC (2007) Promoting joint attention in toddlers with autism A parent-mediated developmental model. J Autism Dev Disord 37: 1562-1575.

8. McCabe H (2007) Parent's Advocacy In The Face Of Adversity: Autism and Families in the People's Republic of China. Focus On Autism And Other Dev Disabilities 22: 39-50.

9. Attwood T (1997) Asperger's Syndrome: A Guide for Parents and Professionals Jessica Kinsley publishers.

10. Bolte S (2014) Is autism curable? Dev Med \& Child Neurology 56: 927-931. 